\title{
C. Araujo Sánchez y la crítica museológica en el siglo XIX
}

\author{
M. a ÁngeLEs LAYUNO Rosas *
}

El museo, desde un punto de vista institucional, tiene su origen en los siglos XVIII y XIX, en los que se produjo un clima ideológico adecuado que se materializó culturalmente en estas entidades.

Decisiones de soberanos de abrir sus colecciones al público, influidos sin duda por el pensamiento ilustrado; las consecuencias de la Revolución Francesa y del Imperio Napoleónico, son decisivos a la hora de entender la génesis y el carácter de la mayoría de los museos europeos.

En el caso español, según J. A. Gaya Nuño «la Guerra de la Independencia trae, increíble, peregrina y extemporáneamente, la aparición de los anhelados museos" '.

Así, tras un largo período de gestación, la idea de crear una galería real de pinturas, en germen desde el reinado de Felipe IV, se hacía realidad en el de Fernando VII: el 19 de noviembre de 1819 abría sus puertas el Museo Nacional de Pintura y Escultura del Prado.

Junto a estas decisiones regias, que se producen en la mayor parte de los paises europeos dando lugar a los grandes museos nacionales, en nuestro caso fueron fundamentales, a la hora de entender el establecimiento de una red de museos provinciales de Bellas Artes, las consecuencias de las leyes desamortizadoras dictadas por los gobiernos de Toreno y Mendizábal entre 1835 y 1837, museos que se desarrollaron de una manera heterogénea, a veces, por las propias circunstancias de que partió su creación.

Al asumir el Estado la responsabilidad de conservar todo el conjunto de objetos artísticos y documentos procedentes de los conventos

* Becaria predoctoral. Departamento Historia del Arte U.N.E.D.

Gaya Nuño, J.A.: «Historia y Guía de los Museos de España». Madrid, 1968, pág. 27. 
desamortizados, se hizo necesario elaborar una serie de medidas legislativas encaminadas a organizar una incipiente política museística nacional. Entre éstas destacar la R.O. de 29 de julio de 1837, por la cual se crean las Juntas Científicas y Artísticas Provinciales, encargadas de constituir archivos, bibliotecas y museos. Parece ser que la gestión de estas Juntas no tuvo la eficacia que cabría esperar, y de ahí que el siguiente paso fuese la creación de unas Comisiones Provinciales de Monumentos por R.O. de 13 de junio de 1844, al frente de las cuáles existía una Comisión Central coordinadora de los trabajos que se iban efectuando en las provincias.

No obstante la buena fe gubernamental, toda esta labor no dio los resultados deseados. Entre las múltiples razones de este fracaso, J. Alvarez Lopera ha señalado la falta de remuneración de los componentes de estas Comisiones, así como su falta de autoridad, la escasa subvención que se destinaba a sus operaciones etc. ${ }^{2}$. La "Memoria comprensiva de los trabajos verificados por las comisiones de Monumentos Históricos y Artísticos del Reino desde el primero de julio de 1844 hasta igual fecha de $1845{ }^{3}$ se hace eco de esta situación en la que la mayoría de los proyectos no pasaban del papel.

A pesar de la ralentización que sufría el proceso de creación de museos en nuestro país, empañado en algunos lugares por prácticas no demasiado ortodoxas, como sustracciones, ventas ilegales de obras, falta de atención y conservación etc., con medios escasos y condiciones inadecuadas, abrieron al público varios museos de provincias, que recibían nuevos impulsos desde el poder, como las «Instrucciones para la creación de museos provinciales" por R.D. de 31 de octubre de 1849, o la Ley de Instrucción Pública de 9 de septiembre de 1857, en la que se daba el encargo a los gobernadores de crear un museo provincial en sus respectivas capitales.

A medida que avanzaba el siglo y se asistía a la constitución de los primeros núcleos museísticos, aparecen una serie de textos críticos ante esta problemática de los museos y la museología en España, que se pueden definir a veces, como propuestas, como soluciones a los errores o defectos brevemente enunciados anteriormente.

Entre estas obras, destaca por su interés «Los Museos de España» ${ }^{4}$, del pintor y crítico de arte Ceferino Araujo Sánchez, donde quedan planteados

Es interesante el análisis de los museos de la época isabelina llevado a cabo por ALVAREZ LOPERA, J. en la «Introducción" a "Museos de España». Ed. Everest, León, 1986. págs. 8-19.

3 Madrid, Imprenta Nacional, 1845.

4 Madrid, 1875. 
los temas esenciales del debate museístico del momento, los cuáles comentamos a continuación.

El tono general de su obra es de profundo pesimismo, pero, al mismo tiempo, de actuar como revulsivo frente a tanta inoperancia y abulia gubernamental, apuntando directrices que, a su juicio, serían las correctas para encauzar el programa de museos en España, coincidiendo e ello con otros críticos como V. Poleró, Tubino o Caveda.

En las primeras páginas Araujo plantea el tema del mercado de arte, del mecenazgo y coleccionismo privados, y la promoción de las artes por parte de estas personas y entidades particulares, precisando que «Hace un año emprendió un particular la industria de una exposición permanente para la venta de obras de arte, y lo que hace algún tiempo hubiera sido locura pensar, está dando buenos resultados. Todos los días algún magnate o potentado hace decorar espléndidamente sus salones» ${ }^{5}$.

Asimismo, alude a la labor de fomento de la creación puesta en marcha por corporaciones como el Ateneo Científico y Literario y la Sociedad Económica Matritense.

Unido a ello, y ya refiriéndose al museo, considera conveniente como medio de ampliar o enriquecer las colecciones de un museo, y siguiendo los ejemplos extranjeros, el sistema de donaciones o legados de particulares, que serían «recompensados con cruces y otras distinciones, según la importancia", tema que sigue en plena vigencia en la actualidad. Tenemos noticia de que muchos museos provinciales sólo pudieron abrirse gracias a la iniciativa particular, aunque este tipo de actuaciones no debió de ser la tónica general, si bien a fines del siglo xIX y principios del $x x$ se produce un aumento de las iniciativas privadas.

A nivel estatal, Araujo propone una política museística centralizada, con especial interés en los museos de Madrid, a partir de los cuáles y de la reordenación de sus colecciones, se tendiera a la consecución de un Gran Museo Nacional o Museo del Rey (esta última denominación en honor a Fernando VII).

En lo referente a la colección de este museo, no debían escatimarse esfuerzos porque "contenga el número más completo de obras de los distintos autores necesarios para poder estudiar bien la historia del Arte...".

Araujo Sánchez, C.: "Los Museos de España", Madrid, 1875, pág. 10. A partir de esta cita, mientras no se indique lo contrario, todas las citas corresponden al mismo autor y obra. Se indicará la página puntualmente. 


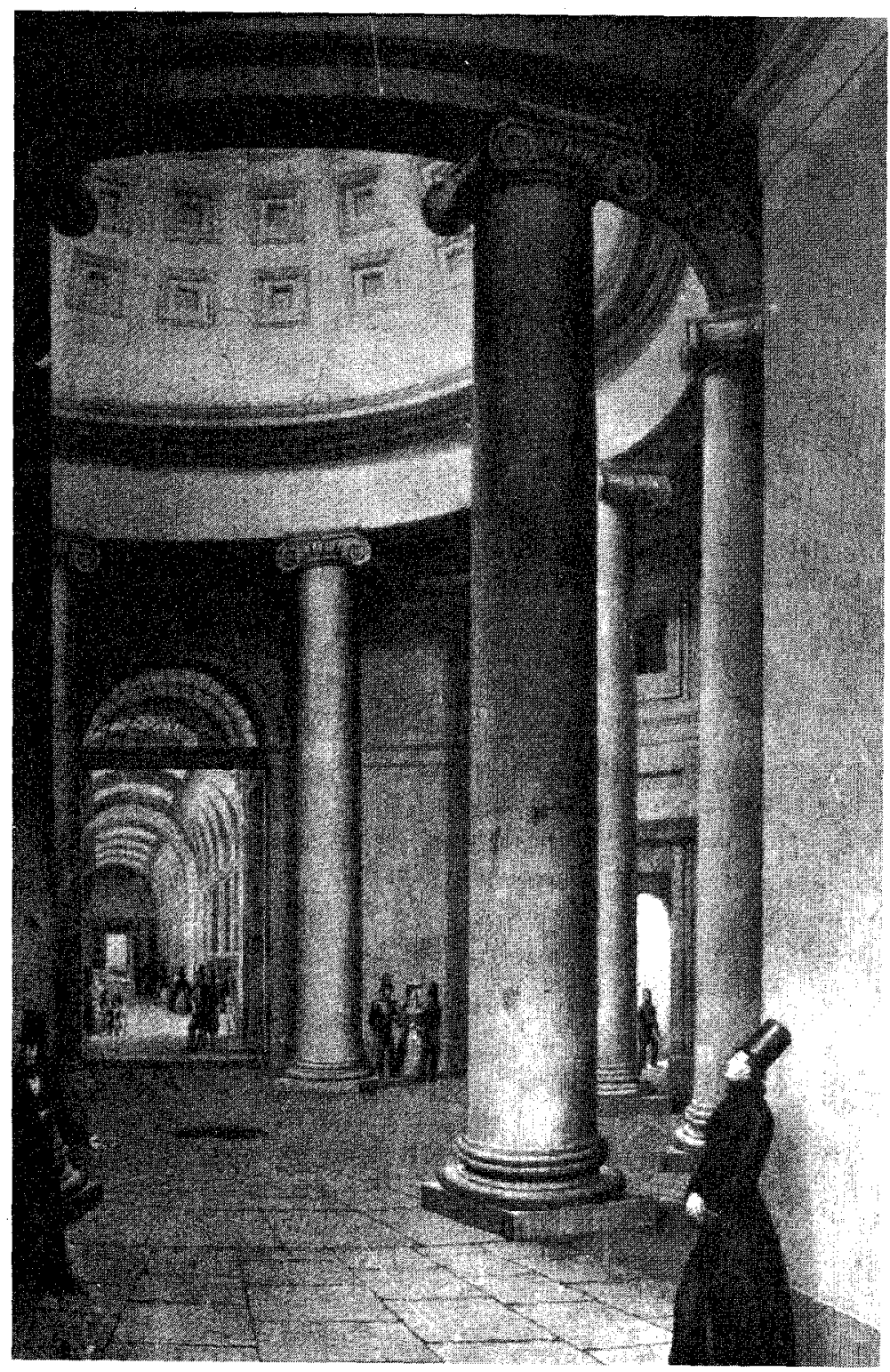

Fig. 1. 
Los métodos para cubrir las evidentes lagunas no sólo debían centrarse en una sabia política de adquisiciones, sino también basarse en una política de coordinación e intercambio de obras entre los distintos museos del Estado, e incluso con algunos museos extranjeros, sin olvidar los recursos que ofrecen los fondos de las iglesias, que cederían sus obras a cambio de reproducciones.

En este punto Araujo se muestra sumamente partidista, a favor de la gran colección de Madrid, y no ve inconveniente en «despojar» de sus fondos a otros museos y monumentos eclesiásticos. Ante la hostilidad provincial que posiblemente originara esta primacía de Madrid, opina que las quejas provienen de la envidia más que de la razón y no tienen justificación desde que, «era menester que hubieran las capitales siquiera dado muestras de actividad e ilustración en las cosas que quedaban a su iniciativa y lejos de esto siempre ha languidecido lastimosamente todo aqueIlo en que no ha intervenido el Gobierno central de una manera directa»6.

El autor dedica una parte de su obra a los museos de Madrid, entrando en el tema de la reordenación de sus colecciones. Señala tres museos importantes: el Museo Real o del Prado, el Nacional (Museo de la Trinidad) y el de la Academia de Bellas Artes de San Fernando.

En cuanto al prirnero, hace una breve historia de la procedencia de sus fondos, el coleccionismo regio, lo cual justifica las lagunas de sus colecciones:

«... faltan en él obras de casi todos los artistas españoles y extranjeros, anteriores al siglo XVI; faltan también las escuelas modernas y contemporáneas, y aun en las mismas escuelas de los siglos XV y XVII, muchos nombres de autores de primero y segundo orden... por su importancia, como para la historia del Arte» ?.

En este punto es preciso hacer algunas aclaraciones sobre las funciones que debía satisfacer el museo en la época considerada: el desarrollo del gusto y la misión pedagógica. Para cumplir ese objetivo de aprendizaje, de estudio, al que se refiere Araujo en repetidas ocasiones, era preciso adoptar, en la presentación de las obras, el principio ilustrado de "gallería progressiva», reclamada desde finales del siglo XVIII. Frente al principio barroco de la "Miscellaneae" (presentación de las obras más por contrastes que por analogías, mezclando autores, géneros, períodos 
etc.) se opta por una presentación racional, lineal, cronológica de la historia del arte.

Por otra parte, el fomento del gusto se consideraba consustancial al museo.

En palabras de Araujo, «Pocas cosas pueden contribuir más al desarrollo del gusto que la organización de los museos existentes y la creación de otros...», insistiendo más adelante en ello al resumir las tres funciones: «... para que pudieran servir de enseñanza y ejercer la influencia en los adelantos del gusto y de la industria...».

El tema de las relaciones entre Arte e Industria está en pleno debate en 1875 y así lo hace notar nuestro autor «En la Industria va el Arte tomando la parte que debe...». En este período en que comienza la especialización de los museos surgen con este fin los museos de Reproducciones Artísticas y de Artes Industriales.

Otro museo importante de Madrid era el Museo Nacional, llamado Museo de la Trinidad, por estar ubicado en el convento de este nombre. Este tenía su origen en la desamortización de los bienes eclesiásticos ${ }^{8}$.

Fue creado por R.O. de 31 de diciembre de 1837, para albergar las obras de arte de los conventos suprimidos de las provincias de Madrid, Avila y Segovia.

Varios autores han coincidido en señalar como causas de su prematura supresión (por decretos de 1870 y. 1872) y la consiguiente fusión de sus fondos con los del Prado, la escasez de medios económicos, la falta de apoyo estatal, la inadecuación de los locales en que estaba instalado, la ausencia del más mínimo criterio ordenador en la exhibición de sus fondos, unido a la mala calidad de la mayor parte de éstos, por lo general «obras de segundo orden de autores españoles, muy interesantes para la historia de Arte en nuestro país; pero está muy lejos de ser un gran Museo, como algunos creen» ${ }^{9}$.

Sobre las circunstancias de esta fusión que afecta a la tarea de la reordenación de las colecciones nacionales de Madrid, contamos con una

\& Para más información sobre el museo del convento de laTrinidad véase: GaYa NuÑo, J. A.: «El Museo Nacional de la Trinidad. Historia y Catálogo de una pinacoteca desaparecida» en Boletín de la Sociedad Española de Excursiones, 1947, págs. 19-78. Como catálogo de la época es el de Cruzada VillaAmil, G.: «Catálogo provisional, historial y razonado del Museo Nacional de Pinturas, formado de orden del Excelentísimo Sr. Ministro de Fomento, Marqués de la Vega de Armijo". Madrid, Imprenta Manuel Galiano, 1865.

9 Araujo Sánchez, C., op. cit, pág. 24. 
C. Araujo Sánchez y la crítica museológica en el siglo XIX

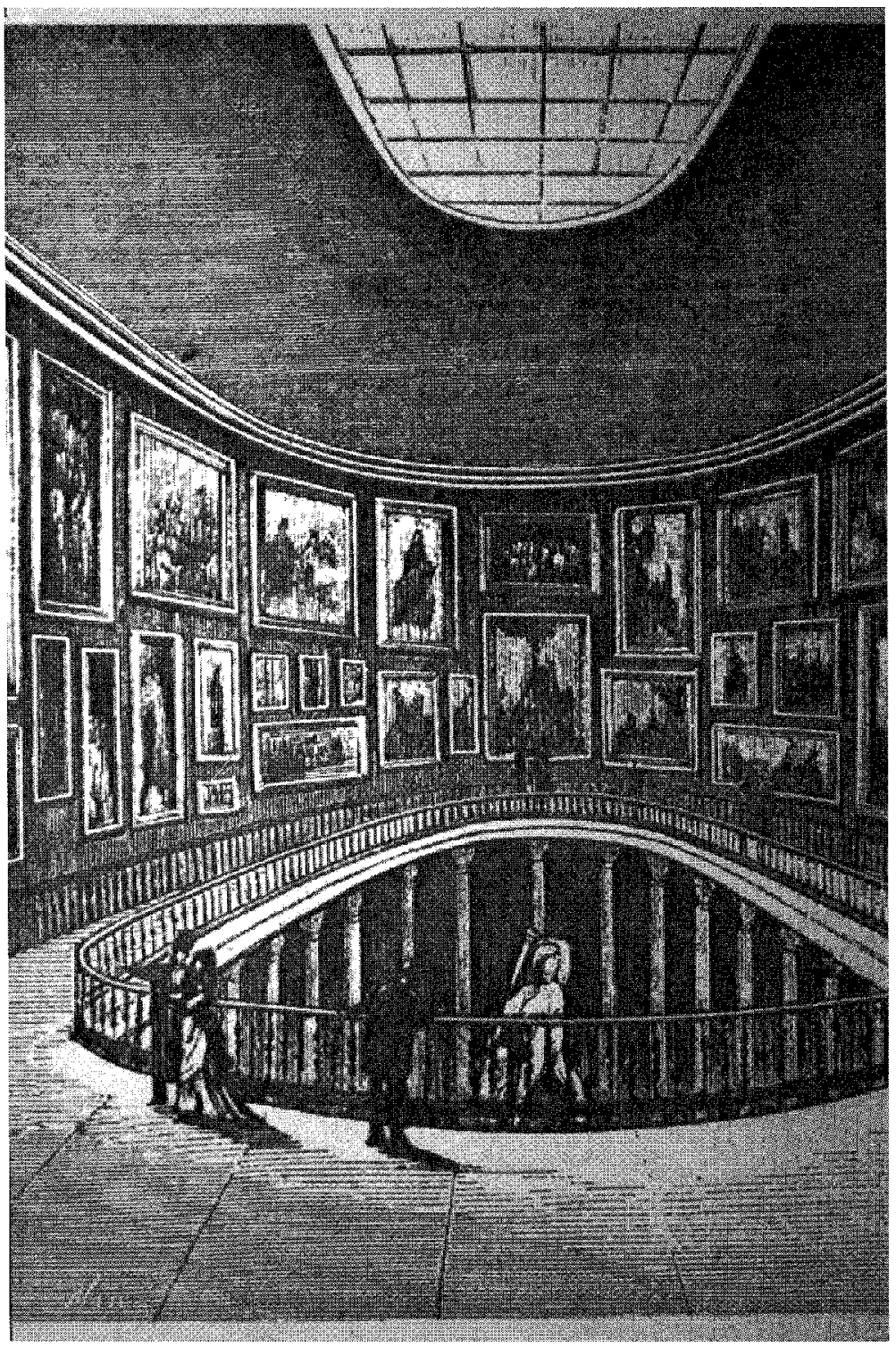

Fig. 2. 
importante fuente de la época: la obra de Vicente Poleró, «Breves observaciones sobre la utilización y conveniencia de reunir en uno sólo los dos museos de pintura de Madrid y sobre el verdadero estado de conservación de los cuadros que constituyen el Museo del Prado" ${ }^{10}$, la cual sorprende por la coincidencia de criterios y puntos de vista con la obra de Araujo Sánchez. Hemos reproducido uno de los párrafos más significativos:

«... Con la reunión de lós dos museos, con algunos cuadros de los museos provinciales, a cambio se entiende de otros que los mismos no conocen; con los repartidos en el Palacio Real de Madrid; los de los Sitios de Aranjuez, El Pardo, Escorial, La Granja y Riofrío; con los de la Academia de San Fernando, y por último con los que en no menor número andan diseminados por algunos templos de España, y que pudieran canjearse por otros parecidos... Entonces el Gran Museo Nacional, cubiertas las lagunas que en punto a la historia del Arte se notan... se alzaría poderoso, siendo el más vasto, el más rico, y el más importante de todos los museos conocidos» ${ }^{11}$.

Como puede observarse, el proyecto museológico de Poleró es prácticamente el mismo que años más tarde nos presenta Araujo.

El tercer museo madrileño que destaca Araujo es la Galería de Pinturas de la Academia de San Fernando. Las Academias se constituyeron desde su fundación, como notables núcleos museológicos de carácter público, debido a que van a ir formando importantes colecciones y realizando exposiciones con sus fondos. En España, junto a la Real Academia de Bellas Artes de San Fernando (fundada en 1752) en Madrid, la Escuela de la Lonja de Barcelona y la Academia de San Carlos de Valencia, derivarían en futuros museos. Estas dos últimas recibieron un fuerte impulso en este sentido por parte de las autoridades francesas en el reinado de José I Bonaparte.

En Madrid, desde 1836 se tienen noticias documentales y gráficas que dan fe del carácter abiertamente público que tenían las exposiciones organizadas por la Academia de San Fernando, fomentando de esta manera la creación plástica pues las convocatorias iban dirigidas a los artistas del momento, al igual que las pensiones en el extranjero. Aparte de estas obras de académicos, la colección de la Academia estaba compuesta por donativos reales y particulares, devoluciones del botín que se llevaron los franceses en 1808 , obras procedentes de los conventos desamortizados etc.

10 Madrid, 1868.

1 Texto reproducido por Alvarez Lopera, J., op. cit. pág. 15. 


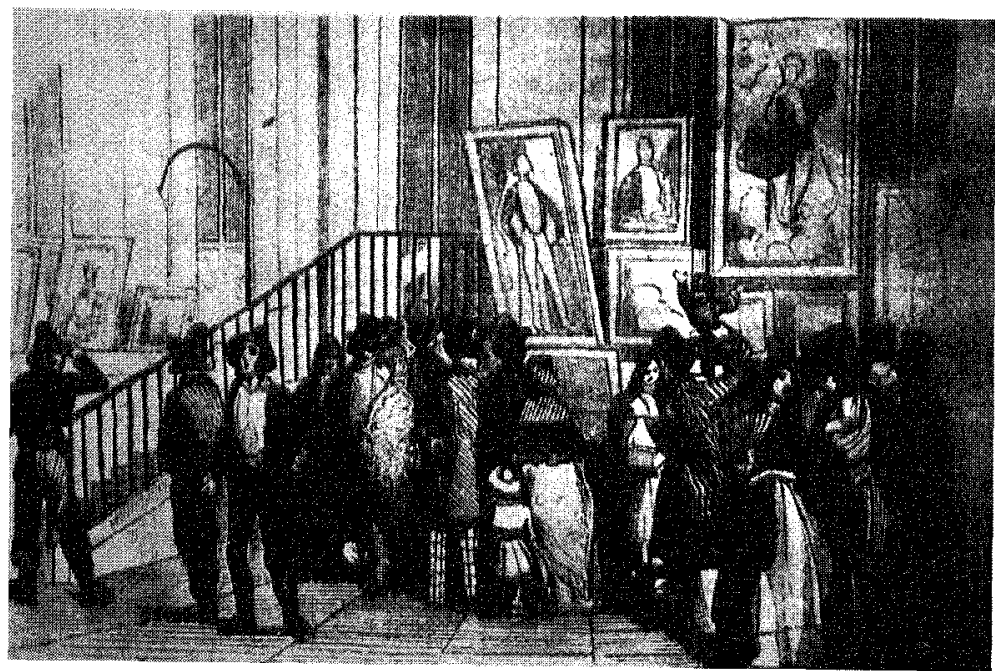

Fig. 3.

En relación a este museo resulta interesante la propuesta expuesta por Caveda en sus «Memorias para la Real Academia de San Fernando», de fusionar sus fondos con los del Prado, como también había sugerido Poleró:

«Muy ventajoso seria agregar a sus pinturas (las del ya Museo Nacional) las existentes en la Academia, constituyendo con todas un magnífico conjunto. Ambos establecimientos pertenecen al estado; ambos se consagran al mismo objeto; ambos abren al público sus respectivas colecciones. ¿Por qué separarlas, cuando de reunidas resultaría uno de los establecimientos más notables de su clase? La necesidad podrá justificar hoy esta separación: continuarla, más aún que una inconveniencia, será una falta inconciliable con nuestra cultura, con el aprecio que las Artes nos merecen, y el empeño de extender y mejorar su enseñanza» ${ }^{12}$.

En la mayoría de estos textos lo que subyace es una crítica a la política cultural del Estado, concretamente en materia de museos, una crítica al estado de la museología en el país, en comparación con los avances que se producían en otros lugares.

12 Texto citado por Araujo Sánchez, op. cit. pág. 25. 
Araujo denuncia en repetidas ocasiones la poca o nula afición que existía hacia las artes y su fomento, lo cual se traducía en la pésima situación de los museos. A su vez, reclama el interés del gobierno hacia estas instituciones mediante una mayor subvención para su correcto funcionamiento. Así, cuando se refiere a los museos de arte sacro formados en las distintas provincias a raíz de la supresión de los conventos, se lamenta del poco interés que existe en estas ciudades por conocerlos y fomentarlos. Critica la ineptitud e ignorancia en materia artística de las comisiones encargadas de organizar y redactar los catálogos, en manos de individuos que no tenían la más mínima formación en arte y que además, trabajaban sin retribución alguna.

Se trata, en suma, de llamar la atención sobre el desafortunado camino por el que avanzaba la labor de las ya citadas Comisiones Provinciales de Monumentos, señalando directamente los errores de base relativos a su gestión.

La falta de todo rigor en la elaboración de estos catálogos iba acompañada de la falta de la más mínima formación museológica, como ya apuntábamos, a la que Araujo se refiere en estos términos:

«... se une lo desordenado de la colocación de las obras, que nunca obedece a sistema alguno. No se encuentran en ninguna parte agrupaciones, ni por escuelas, ni por autores, ni cronológicas. Tablas que reunidas fueron un díptico, ó un tríptico, se hallan desparramadas, y a veces atribuidas a diferente autor unas que otras... Si las condiciones del local no son buenas, no se ha atendido tampoco en la mayor parte de los museos, no en todos, a que las obras más importantes fueran las preferidas para la conveniente colocación; en fin, como almacenes pueden ser considerados mejor que como galerías" ${ }^{13}$.

Todas estas consideraciones podían aplicarse a los museos de Madrid. El Museo de la Trinidad fue el blanco de un mayor número de críticas, por la total inadecuación del edificio donde estaba instalado, la mala presentación de las obras y, sobre todo, por la poca atención prestada a la conservación de las mismas, lo que ocasionaba el deterioro continuo y la pérdida de muchas de ellas.

En lo que respecta a la Academia de San Fernando, así la describe Caveda:

«... Carece, por desgracia, del espacio y las luces convenientes para que pueda ser bien apreciada. Se ven los cuadros repartidos en oscuros salones

13 Araujo, op. cit. págs. 16-17. 
ó tránsitos estrechos, sin otro orden en su colocación que el necesario para conservarlos en buen estado, y como si sólo se pretendiese establecer interinamente un depósito de ricos materiales» ${ }^{14}$.

Por su parte, Araujo propone en su obra varios criterios de ordenación de las obras: cronológico, por naciones, por autores, señalando la necesidad de colocar tarjetones en los cuadros con los datos más precisos para la información del visitante, y añade que el museo «debe estar abierto al público todos los días...» puesto que «... un museo es un establecimiento de tanta enseñanza como una cátedra ó una biblioteca».

Esta función didáctica se hace insistente a lo largo de su texto, y traduce una decidida voluntad por imponer el concepto de museo como lugar formativo y didáctico básicamente.

Para finalizar, en relación al Museo del Prado, Araujo hace los siguientes comentarios: «... pero los defectos del actual (local) no justifican el desarreglo completo en que se encuentra la galería». La crítica se ceba en la mala colocación de las obras, en especial las de gran formato, para concluir que «Todo lo que no sea dar luz cenital á todo el edificio, y construir nuevas galerías hacia la parte del Retiro, será perder tiempo y dinero».

A través de diversas fuentes conocemos el modo en que se disponian los cuadros en el Prado, siguiendo los criterios vigentes en la época, tapizando las paredes. Lo cierto es que hasta bien entrado nuestro siglo, al Prado se le ha criticado el poco cuidado en la disposición de sus obras, el pésimo acondicionamiento de los locales etc., insuficiencias, algunas de las cuáles, se fueron subsanando, fundamentalmente en las últimas décadas del siglo XIX (por referirnos sólo a este período cronológico), a través de varios proyectos de reforma de salas, iluminación, ventilación, seguridad, conservación de su arquitectura etc., si bien el edificio no sufrió la primera ampliación hasta 1914.

No obstante todos los esfuerzos encaminados a solventar algunos de estos problemas, que por otra parte el Prado comparte con la mayoría de los grandes museos nacionales, como la falta de espacio o los criterios de ordenación de las colecciones, no podemos decir que hoy en día no persistan, reavivando un debate iniciado hace un siglo.

En su conjunto, la obra de Araujo Sánchez es un testimonio de primer orden para el conocimiento de lo que fue el proceso de formación de museos en España durante el siglo XIX, un momento cargado de dudas, de

14 Texto citado por Araujo, op. cit. pág. 25. 
errores, en el que no estaba claro lo que debía ser un museo, sus funciones etc. La poca atención prestada a este tema, a los edificios, a la presentación de las piezas y su correcta conservación, desembocaría en el descrédito y la leyenda negra que pesó sobre estas instituciones, hasta el punto de ser consideradas «Panteones de Arte», cementerios, almacenes o depósitos en el mejor de los casos.

Los textos de todos los autores del siglo xIX citados a lo largo del artículo, especialmente el de Ceferino Araujo, pueden valorarse como una auténtica crítica museológica en su momento, abriendo un debate sobre museos que no evolucionaría con tanta fuerza hasta prácticamente nuestros días y que nos ayuda a comprender desde el pasado, algunas lagunas y características de nuestra museología actual. 